S4 Table Sensitivity analyses for the influence of individual studies on the pooled prevalence estimates for coal workers pneumoconiosis (CWP) in the United States. Included meta-analyses are for coal workers pneumoconiosis by disease severity (progressive massive fibrosis, advanced coal workers pneumoconiosis), mine type (surface), region (Central Appalachia versus overall United States) and r-type opacities. Each plot shows the calculated prevalence estimates with the named study omitted.

\title{
Progressive massive fibrosis
}

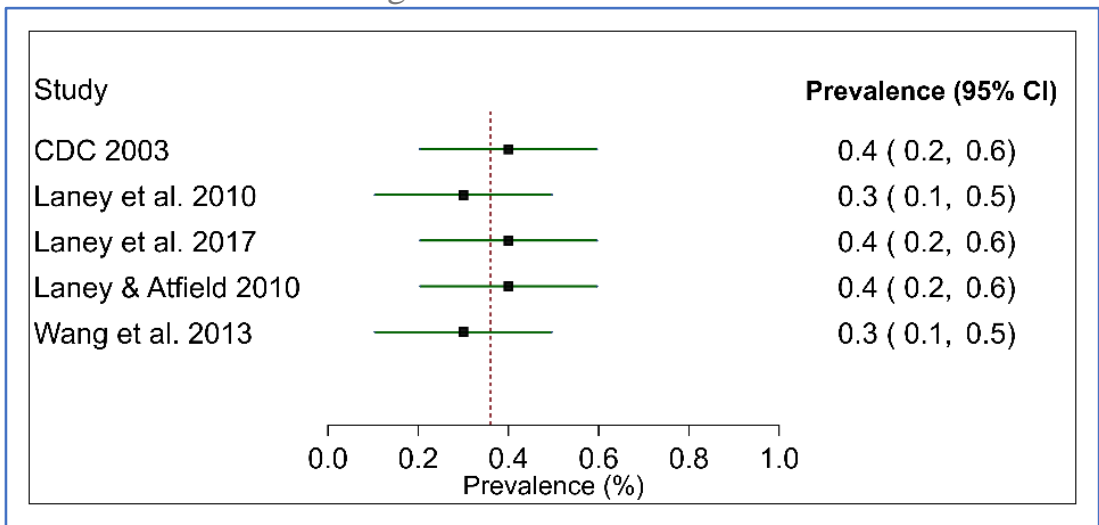

Advanced CWP

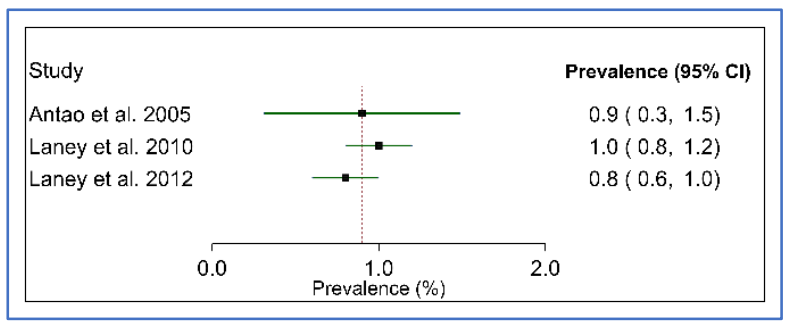

r-type opacities

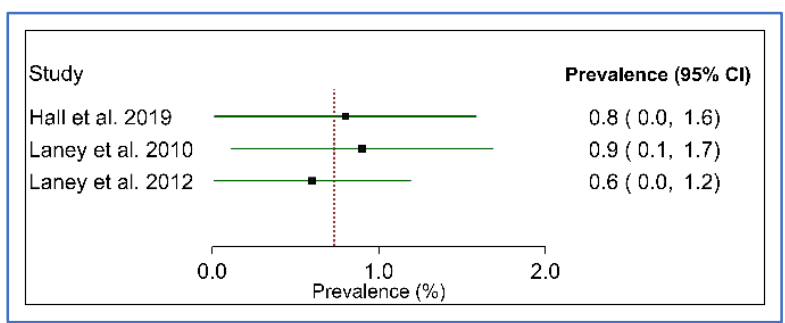

Surface mines-CWP

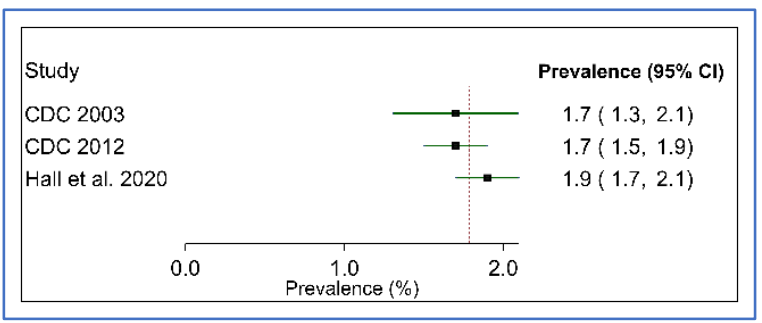

CWP (Central Appalachia, includes states Kentucky, Virginia, and West Virginia in the USA)

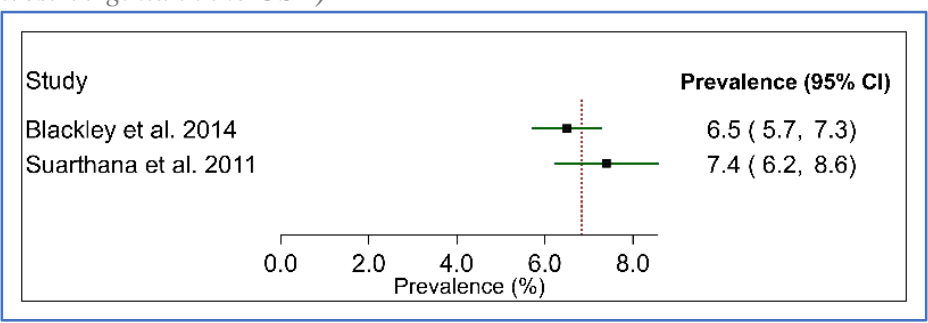

CWP (National, all USA)

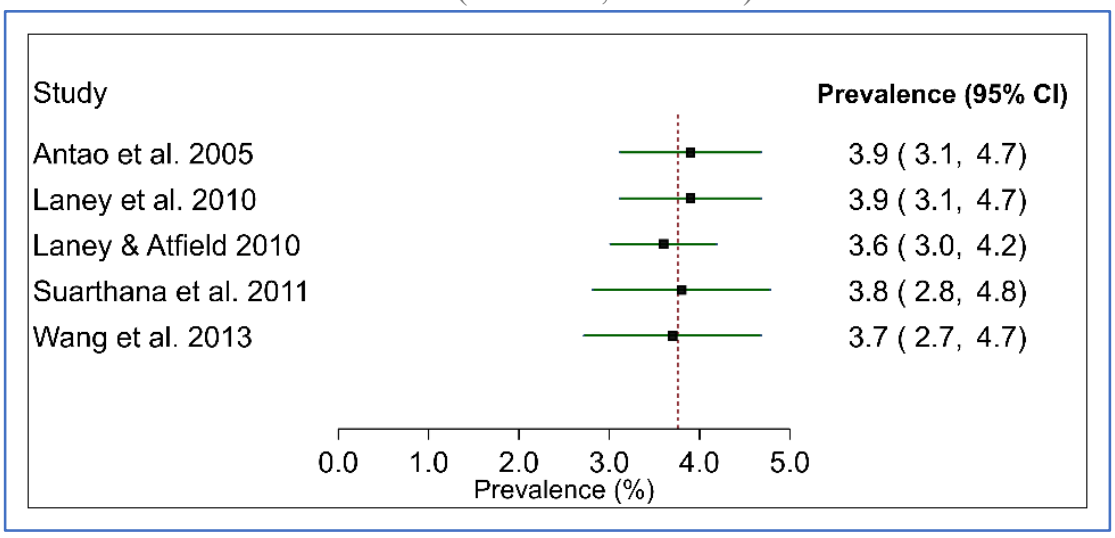


